\title{
Journal of Bacteriology and

\section{Prevalence and Risk Factors of Cryptosporidium Infection in Children Hospitalized for Diarrhea in Guangzhou, China}

Shouyi Chen ${ }^{1 \pi}$, Edward Rob Atwill ${ }^{2,3 \pi}$, Fei Zhong ${ }^{1}$, Yuehong Wei ${ }^{1}$, Shuiping Hou ${ }^{1}$, Juntao Li ${ }^{1}$, Conghui Xu ${ }^{1}$, Chengling Xiao ${ }^{3}$, Zhicong Yang ${ }^{1 \&}$ and $\mathrm{Xunde}$ Shou $i^{2,3^{*} \&}$

${ }^{1}$ Guangzhou Center for Disease Control and Prevention, Guangzhou, Guangdong Province, China

${ }^{2}$ Department of Population Health and Reproduction, University of California Davis, California, USA

${ }^{3}$ Western Institute for Food Safety and Security, University of California Davis, California, USA

"Corresponding author: Xunde Li, Department of Population Health and Reproduction, University of California Davis, California, USA, E-mail: xdli@ucdavis.edu

Received date: May 03, 2017; Accepted date: May 11, 2017; Published date: May 16, 2017

Copyright: (c) 2017 Chen S, et al. This is an open-access article distributed under the terms of the Creative Commons Attribution License, which permits unrestricted use, distribution, and reproduction in any medium, provided the original author and source are credited.

\begin{abstract}
This study was conducted to determine the prevalence, species and risk factors of Cryptosporidium infection in children hospitalized for diarrhea in Guangzhou region of China. A cross-sectional study was conducted to assess the prevalence and risk factors of Cryptosporidium infection in children ( 2 weeks to 10 years old) who were hospitalized for diarrhea. Cryptosporidium oocysts were detected using direct immunfluorescent assay and species were determined by sequencing a fragment ( $800 \mathrm{bp})$ of the 18S rRNA gene. A questionnaire contains host, sociodemographic, family, hygiene, diet, zoonotic, and environmental risk factors was administered to patients to identify key factors associated with infections. The observed Cryptosporidium prevalence was $6.9 \%$ and the true prevalence was estimated to be $9.0 \%$. Cryptosporidium infection was similar between male $(7.4 \%)$ and female $(6.1 \%)$ children and negatively associated with age (i.e., infection was more likely in younger children). Infections in children were significantly associated with family members' diarrhea within past one month. Infection in children in suburban hospitals $(7.8 \%)$ was significantly higher than that in urban hospitals $(2.1 \%)$. The overall prevalence of Cryptosporidium in rainy season was significantly higher than that in non-rainy seasons. DNA sequences of the $18 \mathrm{~S}$ rRNA gene from infected children were $99.12 \%$ to $100 \%$ identical to sequences in the GenBank of C. parvum isolates from humans and animals. Future works should determine the sources of zoonotic Cryptosporidium and routes of waterborne exposure in the rainy season in this region.
\end{abstract}

Keywords: Cryptosporidium; Cryptosporidiosis; Children; Diarrhea; Risk factors; Genotype

\section{Introduction}

Since the establishment of medical importance of Cryptosporidium in late seventies when clinical cases in humans were documented [1], Cryptosporidium infection continues to be a significant public health problem globally given the parasites is an important cause of diarrhea in susceptible hosts [2]. Worldwide, the prevalence of cryptosporidiosis ranges from $1 \%$ to $4.5 \%$ in developed countries and $3 \%$ to $20 \%$ in developing countries [3]. During the past decades, 14 of the $\geq 30$ Cryptosporidium species have been identified to be infectious to humans [4]. Most cases of human cryptosporidiosis are caused by $C$ hominis, a species for which humans is the major or exclusive host, and C. parvum, a zoonotic species that infects neonatal ruminants and a broad range of mammals [5]. Acute cryptosporidiosis cause diarrhea, vomiting, abdominal cramps, anorexia, and fever, among these watery diarrheas are the leading clinical symptoms for young children which lasts 2 to 8 weeks [6]. Early studies measuring prevalence of Cryptosporidium in children in Africa, Southeast Asia and Central and South America demonstrated that acute cryptosporidiosis was a predictor of childhood mortality [7,8]. In a recent global enteric multicenter study in sub-Saharan African and south Asia, Cryptosporidium was one of the top four pathogens attribute to moderate-to-severe diarrhea in 9439 children [9]. In another study testing stools collected from $>2,000$ children aged 0-24 months from Asia, Africa and South America, Cryptosporidium spp. was detected in
$2.0 \%$ stool samples and was among the top five pathogens contributed to diarrhea in the first year of life [10].

The broad host range of Cryptosporidium facilitates environmental dissemination and inter-host and zoonotic transmission through such modes as water, food, direct contact with contaminated surfaces, and close contact to infected persons or animals [11]. Due to the resistance of oocysts to water treatments including chlorination, Cryptosporidium is an important waterborne pathogen. Contaminations through drinking water or recreational water have been frequently responsible for major outbreaks of cryptosporidiosis [12-14]. Foodborne outbreaks of cryptosporidiosis have been linked to fresh vegetables $[15,16]$, unpasteurized milk [17], and fresh-pressed apple cider [18]. Although foodborne outbreaks have been rare, global foodborne cryptosporidiosis could be underestimated [19]. For children, attending to daycare centers is another pathway of exposure to outbreaks of cryptosporidiosis [20,21]. Because early childhood children is more susceptible of Cryptosporidium infection, reducing exposure to the biologic source of Cryptosporidium and identifying key risk factors for the exposure is important toward the goal of reducing the incidence of cryptosporidiosis in children.

In developing countries including China cryptosporidiosis is a common cause of persistent diarrhea among children [22]. Cryptosporidium infection in children has been sporadically reported in different regions of China including Jiangsu Province [23,24], Shanghai [25], Changsha [26], Anhui province [27], Yunnan Province [28], and Anhui province [29]. Guangzhou, located just the south of the Tropic of Cancer, is the capital and largest city of Guangdong 
province in South China. Little is known about the prevalence of Cryptosporidium and key risk factors attribute to the infection in children in this tropical metropolitan region. We conducted a crosssectional epidemiologic study in diarrheic children patients who were hospitalized in Guangzhou City to determine the prevalence and dominate species of Cryptosporidium in children and to identify risk factors associated with the infection in this region.

\section{Material and Methods}

\section{Enrollment of pediatric patients hospitalized for diarrhea}

Based on the existing sentinel hospital networks for disease surveillance of Guangzhou Center for Disease Control and Prevention (GZCDC), 5 hospitals were enrolled for this study between 2011 and 2012. Among the 5 hospitals, Huadu district hospital and Taihe hospital were categorized as suburb hospitals while Guangdong Women and Children hospital, Yuexiu District hospital and Zengcheng District hospital as urban hospitals according to the distances to the center of Guangzhou metropolitan. The study population composed of children ranging from two weeks to 10 years old who had been hospitalized primarily due to diarrhea. Patients were admitted based on parents or guardians' agreement of voluntary participation and regardless of their point of origin. A total of 597 cases were referred to this study by either pediatrician or nurse responsible for the hospital wards in the five hospitals. All patients were residents of the Guangzhou metropolitan. Diarrhea was defined as acute $\geq 2$ acute loose or watery stools in the previous 24 hours that was still present when the fecal specimen was collected at the hospitals. Patients who developed diarrhea after admission to the hospitals were excluded.

\section{Specimen collection and detection of Cryptosporidium}

A single fecal sample was collected from each patient by parents and placed into a disposable single use plastic cup. Samples were transported to the Laboratory at GZCDC and preserved in $2.5 \%$ potassium dichromate solution and stored at $4^{\circ} \mathrm{C}$. Within one week of sample collection, a direct immunofluorescent assay (DFA) was used to detect Cryptosporidium oocysts as previously described [30,31]. Briefly, 5 grams of fecal sample (use $1 / 3$ if $<5 \mathrm{~g}$ ) was dispersed and suspended in $40 \mathrm{ml}$ PBS, homogenized, and filtered through 4-layer gauze. Fecal solutions were centrifuged at $1000 \mathrm{~g}$ for $10 \mathrm{~min}$, the supernatants were discarded by aspiration and the sediment was resuspended 1:1 (v/v) in sterile distilled water. The final fecal suspensions were homogenized and $10 \mu \mathrm{l}$ was used for making slides using a FITC antibody kit (Aqua-Glo G/C, Waterborne Inc.). Slides were examined using a fluorescent microscope at $\times 200-400$ amplification. A sample was defined positive of Cryptosporidium if one or more oocysts were detected.

\section{Retrieving information of risk factors of exposure to Cryptosporidium}

In consultation with pediatricians and nurses and in consideration of local culture and diet traditions of Guangzhou, we developed a comprehensive questionnaire covers risk factors potentially attribute to the routes of exposure and transmission of Cryptosporidium in children. The questionnaire included risk factor categories on 1) hosts: age, gender, and nutrition status; 2) sociodemographic and intrafamilial factors: types of dwelling, attendance of daycare of pre-school children, lunch service of school children, and family members with gastrointestinal symptoms within one month; 3) hygiene factors: hands washing before meal and after using toilets, and types of household toilets (indoor vs. outdoor); 4) zoonotic factors: owning pets or not, whether pets have diarrhea within one month, whether contact with livestock or zoo animals, and whether family members work at animal agriculture facility or zoo; 5) diet factors: whether consumption of raw vegetables, raw fruits without peeling or washing, raw milk, and source and treatment of household drinking water; 6) environmental factors: season, proximity of environmental water (e.g. river or lake), sewage effluent canal near dwelling, and recent contact to water (river, lake, swimming pool). The questionnaire was administered to all patients by trained nurses based on agreement of voluntary participation by patients' parents or primary guardians.

\section{Molecular characterization of Cryptosporidium}

PCR and sequencing of a fragment of the 18S rRNA genes were used for genotyping Cryptosporidium. Microscopic positive fecal samples were exposed to 5 cycles of freeze $\left(-80^{\circ} \mathrm{C}\right)$ and thaw $\left(+70^{\circ} \mathrm{C}\right)$ then $0.2 \mathrm{~g}$ were used for DNA extraction using the QIAamp DNA Stool Mini Kit (Qiagen). PCR amplification of a fragment ( $\sim 30 \mathrm{bp})$ of the $18 \mathrm{~S}$ rRNA gene by nested-PCR was performed using primers and cycling conditions as previously described [32,33] using AmpliTaq DNA polymerase (Thermo Fisher Scientific). DNA template of $C$. parvum isolated from calves from a local dairy farm and a negative control without DNA template were included. Products of the secondary PCR were purified using the QIAamp DNA Mini Kit (Qiagen). Purified DNA was sequenced at both directions at a commercial DNA sequencing laboratory (Invitrogen, Guangzhou) where an ABI 3730 Capillary Electrophoresis Genetic Analyzer (Applied Biosystems) were used for sequencing. Sequences were analyzed and consensus sequences were generated using the Vector NTI Advanced 11 software. Consensus sequences were compared to Cryptosporidium sequences and genotypes in the GenBank using NCBI's online nucleotide BLAST tool with the default algorithm parameters.

\section{Statistical Analysis}

Statistical analysis was performed on data using SPSS 17.0 software by applying Chi-Square test and statistical significant differences $(\mathrm{p}<$ 0.05 ) between various groups were calculated. The multivariate forward stepwise logistic regression was conducted to test the factors associated with Cryptosporidium infection. The independent variable input in the regression model of Cryptosporidium infection included all categories of risk factors.

\section{Ethics Statement}

Involvements of human subjects in this study were approved by the GZCDC Ethics Review Board for Medical Research. Parents or guardians provided informed consents on behalf of their children for answering questions in the questionnaire and for collecting specimen from children. All parents or guardians preferred providing oral informed consents, which was documented by checking the box of "Agree" on top of the sheet of questionnaire administered to individual patient. The GZCDC Ethics Review Board for Medical Research approved the use of oral consents for this study. 
Citation: Chen S, Atwill ER, Zhong F, Wei Y, Hou S, et al. (2017) Prevalence and Risk Factors of Cryptosporidium Infection in Children Hospitalized for Diarrhea in Guangzhou, China. J Bacteriol Parasitol 8: 308. doi:10.4172/2155-9597.1000308

Page 3 of 8

\section{Results}

\section{Prevalence of Cryptosporidium in children with diarrhea}

Among the 597 diarrheic children $\leq 10$ years of age who had been taken to hospital wards, the observed prevalence of Cryptosporidium infection was $6.9 \%$ (41/597). We adapted the equation from our previous study using the same DFA method [34] to estimate the true prevalence of Cryptosporidium among the study population of diarrheic children:

$$
\text { True prevalence }=\frac{\text { Apparent prevalence }+\mathrm{Sp}-1}{\mathrm{Se}+\mathrm{Sp}-1}
$$

whereby the observed prevalence was $6.9 \%$ and the sensitivity (Se) and specificity (Sp) were the diagnostic attributes of the DFA assay when applied to our study population of children with diarrhea. According to literature, specificity (Sp) of the DFA assay was estimated to be $100 \%$ for diagnosing Cryptosporidium oocysts from human fecal samples [35-37] and cattle and calf fecal samples [30,31]. The sensitivity of DFA assay for diagnosing of Cryptosporidium oocysts in fecal samples from clinical diarrheic children $\leq 10$ years of age was $77 \%$ as previously determined [34]. Based on the above equation, the true prevalence of Cryptosporidium infection in our studied population of diarrheic children was estimated to be $9.0 \%$. The prevalence of Cryptosporidium in pediatric patients from different hospitals did not vary significantly but difference among hospitals could be potentially significant given the $\mathrm{P}$ value $(0.055)$ was close to 0.05 (Table 1). The majority of referred children patients were from 'suburb' hospitals and the observed prevalence of Cryptosporidium in patients from suburb hospitals (7.8\%) was significantly higher $(\mathrm{P}=0.041)$ than that in patients from urban hospitals $(2.1 \%)$ Table 1.

\begin{tabular}{|c|c|c|c|}
\hline Categories & $\begin{array}{l}\text { No. (\%) of } \\
\text { patients }\end{array}$ & $\begin{array}{l}\text { No. (\%) positive of } \\
\text { Cryptosporidium }\end{array}$ & $\begin{array}{l}P \\
\text { value }\end{array}$ \\
\hline \multicolumn{3}{|l|}{ Hospital } & 0.055 \\
\hline Huadu District hospital & $162(27.1)$ & $10(6.2)$ & \\
\hline $\begin{array}{l}\text { Provincial Women and Children } \\
\text { hospital }\end{array}$ & $47(7.9)$ & $2(4.3)$ & \\
\hline Taihe hospital & $338(56.6)$ & $29(8.6)$ & \\
\hline Yuexiu District hospital & $15(2.5)$ & $0(0.0)$ & \\
\hline Zengcheng District hospital & $35(5.9)$ & $0(0.0)$ & \\
\hline Total & 597 & $41(6.9)$ & \\
\hline \multicolumn{3}{|l|}{ Type of hospital } & 0.041 \\
\hline Urban & $97(16.2)$ & $2(2.1)$ & \\
\hline Suburb & $500(83.8)$ & $39(7.8)$ & \\
\hline
\end{tabular}

Table 1: Prevalence of Cryptosporidium in children hospitalized for diarrhea in five hospitals in Guangzhou, 2011-2012.

\section{Risk factors associated with Cryptosporidium prevalence in children with diarrhea.}

Host, sociodemographic and family risk factors: Numbers of participants responded to questions of host, sociodemographic and family risk factors along with answers were summarized in Table 2. The prevalence of Cryptosporidium was also further stratified according to answers to questions. Diarrhea were approximately evenly distributed between male (58.6\%) and female (41.4\%) children and prevalence of Cryptosporidium was also approximately evenly distributed between male (7.4\%) and female $(6.1 \%)$ children, with no significant difference $(\mathrm{P}=0.519)$. A trend of negative association between child age and the odds of $C$. parvum infection was observed, highest prevalence $(8.5 \%)$ in children $<6$ month old and lowest $(2.5 \%)$ in children $>3$ years old Table 2 . Although the differences were not statistically significant $(\mathrm{P}=0.373)$, results are in consistent with that younger hosts are more vulnerable to Cryptosporidium infection.

\begin{tabular}{|c|c|c|c|c|}
\hline Risk factors & \multicolumn{2}{|c|}{$\begin{array}{l}\text { No. (\%) of patients } \\
\text { responded } \\
\text { questionnaire }\end{array}$} & $\begin{array}{l}\text { No. (\%) positive } \\
\text { of } \\
\text { Cryptosporidium }\end{array}$ & $\begin{array}{l}P \\
\text { valu } \\
\text { e }\end{array}$ \\
\hline \multicolumn{5}{|l|}{ Host } \\
\hline \multicolumn{4}{|l|}{ Age } & $\begin{array}{l}0.37 \\
3\end{array}$ \\
\hline$\leq 6$ month & \multicolumn{2}{|l|}{$130(21.8)$} & $11(8.5)$ & \\
\hline$\leq 12$ month & \multicolumn{2}{|l|}{$184(30.8)$} & $14(7.6)$ & \\
\hline$\leq 3$ year & \multicolumn{2}{|l|}{$202(33.8)$} & $14(6.9)$ & \\
\hline$>3$ year & \multicolumn{2}{|l|}{$81(13.6)$} & $2(2.5)$ & \\
\hline \multicolumn{4}{|l|}{ Gender } & $\begin{array}{l}0.51 \\
9\end{array}$ \\
\hline Male & \multicolumn{2}{|l|}{$350(58.6)$} & $26(7.4)$ & \\
\hline Female & \multicolumn{2}{|l|}{$247(41.4)$} & $15(6.1)$ & \\
\hline \multicolumn{4}{|l|}{ Nutrition status } & $\begin{array}{l}0.81 \\
5\end{array}$ \\
\hline Good nutrition & \multicolumn{2}{|l|}{$425(96.8)$} & $27(6.4)$ & \\
\hline Malnutrition & \multicolumn{2}{|l|}{$14(3.2)$} & $1(7.1)$ & \\
\hline \multicolumn{5}{|c|}{ Sociodemographic and familial } \\
\hline \multicolumn{4}{|l|}{ Types of dwelling } & 0.13 \\
\hline Own property & $309(62.3)$ & 20( & $6.5)$ & \\
\hline Rental shared & $17(3.4)$ & $0(0$ & & \\
\hline Rental alone & $170(34.3)$ & 18( & 10.6) & \\
\hline \multicolumn{4}{|c|}{ Pre-school child attends daycare } & $\begin{array}{l}0.57 \\
7\end{array}$ \\
\hline Yes & $51(9.7)$ & \multicolumn{2}{|c|}{$5(9.8)$} & \\
\hline No & $476(90.3)$ & \multicolumn{2}{|c|}{$35(7.4)$} & \\
\hline $\begin{array}{l}\text { Source of lunch for } \\
\text { students }\end{array}$ & -- & -- & & -- \\
\hline \multicolumn{4}{|c|}{ Family members had diarrhea within previous month } & $\begin{array}{l}0.04 \\
7\end{array}$ \\
\hline Yes & $40(7.2)$ & $6(1$ & $5.0)$ & \\
\hline No & $514(92.8)$ & 32( & $6.2)$ & \\
\hline
\end{tabular}

Table 2: Prevalence of Cryptosporidium in children hospitalized for diarrhea in Guangzhou, stratified by host, sociodemographic, and family factors. ( ${ }^{*}$ The majority of patients were pre-school children 
Citation: Chen S, Atwill ER, Zhong F, Wei Y, Hou S, et al. (2017) Prevalence and Risk Factors of Cryptosporidium Infection in Children Hospitalized for Diarrhea in Guangzhou, China. J Bacteriol Parasitol 8: 308. doi:10.4172/2155-9597.1000308

hence only 20 patients answered this question and all were negative of Cryptosporidium).

\begin{tabular}{|c|c|c|c|}
\hline Risk factors & $\begin{array}{l}\text { No. (\%) of } \\
\text { responded } \\
\text { questionnaire }\end{array}$ & $\begin{array}{l}\text { No. } \quad(\%) \text { positive of } \\
\text { Cryptosporidium }\end{array}$ & $P$ value \\
\hline \multicolumn{4}{|l|}{ Hygiene } \\
\hline \multicolumn{2}{|l|}{ Wash hands before meal and after using the toilet } & & 0.752 \\
\hline Yes & $393(71.5)$ & $28(7.1)$ & \\
\hline No & $157(28.5)$ & $10(6.4)$ & \\
\hline Types of toilets & & & 0.486 \\
\hline Indoor & $556(98.4)$ & $39(7.0)$ & \\
\hline Outdoor & $9(1.6)$ & $1(11.1)$ & \\
\hline \multicolumn{4}{|l|}{ Diet } \\
\hline Eating raw vegetables & & & 0.861 \\
\hline Yes & $153(26.8)$ & $10(6.5)$ & \\
\hline No & $417(73.2)$ & $29(7.0)$ & \\
\hline \multicolumn{2}{|l|}{ Eating raw fruits without peeling or washing } & & 0.367 \\
\hline Yes & $360(63.4)$ & $28(7.8)$ & \\
\hline No & $208(36.6)$ & $12(5.8)$ & \\
\hline Drink raw milk & & & 0.87 \\
\hline Yes & $400(72.2)$ & $27(6.8)$ & \\
\hline No & $154(27.8)$ & $11(7.1)$ & \\
\hline Source of household drinking water and treatment & -- & -- & -- \\
\hline \multicolumn{4}{|l|}{ Zoonotic exposure } \\
\hline Pet contact & & & 0.433 \\
\hline Yes & $66(11.1)$ & $3(4.5)$ & \\
\hline No & $530(88.9)$ & $37(7.0)$ & \\
\hline \multicolumn{2}{|l|}{ Pet had diarrhea within 30 days } & & 0.46 \\
\hline Yes & $5(7.6)$ & $0(0)$ & \\
\hline No & $61(92.4)$ & $3(4.9)$ & \\
\hline \multicolumn{2}{|l|}{ Contact livestock within past 2 months } & & 0.113 \\
\hline Yes & $18(3.1)$ & $0(0)$ & \\
\hline No & $554(96.9)$ & $38(6.9)$ & \\
\hline \multicolumn{2}{|l|}{ Contact zoo animals within past 2 months } & & 0.362 \\
\hline Yes & $6(1.1)$ & $0(0)$ & \\
\hline No & $565(98.9)$ & $38(6.7)$ & \\
\hline \multicolumn{2}{|l|}{ Family member works with livestock or zoo animals } & & 0.324 \\
\hline Yes & $7(1.2)$ & $0(0)$ & \\
\hline
\end{tabular}


Table 3: Prevalence of Cryptosporidium in children hospitalized for diarrhea in Guangzhou, stratified by hygiene, diet habit, and zoonotic factors $\left({ }^{*}\right.$ All patients drank boiled tap water in household).

Among patients whose parents answered the question about nutrition status, $96.8 \%$ children were in good nutrition and the rest $3.2 \%$ were in malnutrition. Prevalence of Cryptosporidium in children with good or malnutrition status was not significantly different ( $P=0.815$ ) (Table 2). Among sociodemographic and family risk factors, no significant difference of prevalence of Cryptosporidium were found associated with types of dwellings, attending to daycare for pre-school children and lunch types of school children. However, the prevalence of Cryptosporidium in children with family members had diarrhea within 30 days $(15.0 \%)$ was significantly higher $(\mathrm{P}=0.047)$ than that in children without family members had diarrhea (6.2\%) (Table 2).

Hygiene, diet, and zoonotic risk factors: Numbers of participants responded to questions of hygiene, diet, and zoonotic risk factors along with answers were summarized in Table 3. The prevalence of Cryptosporidium was also further stratified according to answers to questions. All participants that responded to questionnaires claimed drinking boiled tap water in houses. Prevalence of Cryptosporidium in children was not statistically associated with any hygiene, diet, and zoonotic risk factors (Table 3).

Environmental risk factors: No patients had contact of river, lake, or other surface water and no swimming within the past two months and no sewer or wastewater effluent nearby dwelling (data not shown). Guangzhou is in the tropical region that has a summer and monsoon season from June to September. The monthly prevalence of Cryptosporidium in children is shown in Figure 1. The prevalence of Cryptosporidium in the main summer rainy season (July to August) was significantly higher than that in non-rainy seasons $(\mathrm{P}=0.046)$

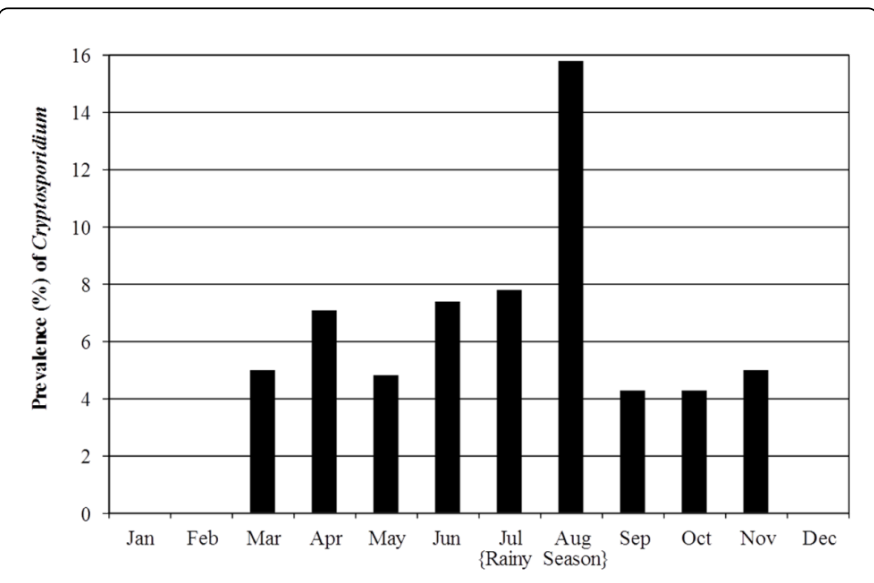

Figure 1: Seasonal prevalence of Cryptosporidium in children hospitalized for diarrhea in Guangzhou, 2011-2012 (July through August is the main summer rainy season in this tropical region).

\section{Genotyping of Cryptosporidium from children with diarrhea}

Among the 41 samples microscopic positive of Cryptosporidium, 10 samples were successfully genotyped by PCR and sequencing a fragment of the $18 \mathrm{~S}$ rRNA gene. Alignment of DNA sequences divided the 10 samples into four variants of $C$. parvum: 7 isolates in variant 1 (KU198182), 1 isolate in variant 2 (KP858925), 1 isolate in variant 3 (KU198180), and 1 isolate in variant 4 (KU198181) (Table 4). Sequences of the four variants were highly homogeneous (99.6\%-99.9\% identical among the shortest sequence of $797 \mathrm{bp}$ ). Two isolates were from Taihe hospital while other 5 isolates of variant 1 were from Huadu District hospital. The isolates of variants 2, 3, and 4 were from Zengcheng District hospital, Huadu District hospital, and Yuexiu hospital respectively. According to BLAST analysis conducted on January 23, 2017, among the 100 max sequences targeted during BLAST analysis, 97, 97, 95, and 94 sequences were $C$. parvum for the variants 1-4 respectively. For variant 1 (KU198182), variant 2 (KP858925), variant 3 (KU198180), and variant 4 (KU198181), the maximum identities to sequences of $C$. parvum were $99.12-100 \%$, $99.12-99.87 \%, 99.25-99.87 \%$, and $99.37-100 \%$ respectively. The top hits of BLAST results of each variant are shown in Table 4.

\section{Discussion}

The observed prevalence of Cryptosporidium in children with diarrhea in Guangzhou region was determined to be $6.9 \%$ and the true prevalence to be $9.0 \%$ adjusted by specificity and sensitivity of the diagnostic method [34]. In other regions of China, prevalence of Cryptosporidium in children in available reports ranged from $0.7-5.06 \%$ [23] and 1.3-9.9\% [24] in Jiangsu Province; 1.3\% [27] and 2.14-5.19\% [29] in Anhui Province; 4.05-7.14\% in Changsha [26] and $5.29 \%$ in Yunnan Province [28]. In other tropical developing countries, Cryptosporidium prevalence has been reported ranges from $1.1 \%$ to $18.7 \%$ [34] in Brazil and 29.6\% in the State of Puebla of Mexico [38]. Although the sensitivities of diagnostic methods in different studies could affect the real prevalence versus observed prevalence reported, overall, prevalence of Cryptosporidium was estimated to be $3-20 \%$ in developing countries [3]. The prevalence of cryptosporidiosis in children in tropical regions was usually higher (an average of up to 10\%) than in moderate regions [6]. In our study, the observed prevalence and adjusted true prevalence of Cryptosporidium in children in Guangzhou region are within the reported ranges of prevalence. Cryptosporidium as an etiologic agent causing diarrheal illness in children could be underdiagnosed [5]. Currently, Cryptosporidium has not been included in routine parasitological tests of children diarrhea specimen in Guangzhou, our results strongly suggested that Cryptosporidium should be included in the routine tests in future.

Children cryptosporidiosis has been found significantly higher in communities in remote regions compared to those living in major cities in Australia [39,40]. The trend of increased prevalence rate of cryptosporidiosis in children from urban to suburban and rural areas was also observed in Yemen [41]. A review of publications of cryptosporidiosis (between 2002 and 2011) in Arabic countries indicated Cryptosporidium species infection among pediatrics in rural and semiurban areas was higher than in urban areas [42]. Results of our study showed that the prevalence of Cryptosporidium in children hospitalized in suburb hospitals $(7.8 \%)$ was significantly higher 
Page 6 of 8

( $P=0.041)$ than that in children hospitalized in urban hospitals $(2.6 \%)$ (Table 1). Given that pediatric patients visit hospitals proximity to dwellings, results of our study are in consistence with that the risk of Cryptosporidium infection is significantly higher for children live in suburb than those live in urban areas. Although no specific risk factors were identified statistical significantly associated with the higher prevalence of cryptosporidiosis in children in suburban area, future studies are warrant to further investigate hygiene, diet, zoonotic, and environmental risk factors that could cause the higher infection of Cryptosporidium in children living in suburb.

\begin{tabular}{|c|c|c|c|c|}
\hline $\begin{array}{l}\text { C. parvum variant (no. of } \\
\text { isolates) }\end{array}$ & $\begin{array}{l}\text { GenBank accession } \\
\text { no. }\end{array}$ & Highly similar isolates and accession no. in the GenBank & Host & Max. identity (\%) \\
\hline \multirow[t]{4}{*}{$1(7)$} & \multirow[t]{4}{*}{ KU198182 } & C. parvum isolate $36, \mathrm{JX} 298598$ & Human & 100 \\
\hline & & C. parvum isolate $35, \mathrm{JX} 298597$ & Human & 100 \\
\hline & & C. parvum isolate $75, \mathrm{JX} 298601$ & Buffalo & 100 \\
\hline & & C. parvum isolate Swec402, KU892559 & Human & 99.75 \\
\hline \multirow[t]{5}{*}{$2(1)$} & \multirow[t]{5}{*}{ KP858925 } & C. parvum isolate Swec402, KU892559 & Human & 99.87 \\
\hline & & C. parvum isolate UKP7, KM012046 & Human & 99.87 \\
\hline & & C. parvum isolate UKP6, KM012044 & Human & 99.87 \\
\hline & & C. parvum isolate UKP8, KM012040 & Human & 99.87 \\
\hline & & C. parvum, AB746195 & Cattle & 99.87 \\
\hline \multirow[t]{4}{*}{$3(1)$} & \multirow[t]{4}{*}{ KU198180 } & C. parvum isolate M1146-5999, KJ469985 & Horse & 99.87 \\
\hline & & C. parvum isolate BRAcalf72, JN120853 & Calf & 99.87 \\
\hline & & C. parvum isolate GZ500, KU198181 & Human & 99.75 \\
\hline & & C. parvum isolate UKP7, KM012046 & Human & 99.75 \\
\hline \multirow[t]{3}{*}{$4(1)$} & \multirow[t]{3}{*}{ KU198181 } & C. parvum isolate A23G, JX948126 & Animal & 100 \\
\hline & & C. parvum isolate Swec434, KU892560 & Human & 99.88 \\
\hline & & C. parvum isolate Swec402, KU892559 & Human & 99.88 \\
\hline
\end{tabular}

Table 4: Comparison of 18S rRNA gene sequence of Cryptosporidium from children hospitalized for diarrhea in Guangzhou to highly related sequences of Cryptosporidium in the GenBank (BLAST analysis conducted on January 23, 2017).

Among host, sociodemographic and familial, hygiene practice, diet habits, and zoonotic risk factors, only the factor of family members have diarrhea within 1 month was significantly associated with the occurrence of cryptosporidiosis in pediatric patients with diarrhea ( $P=0.047$ ) (Tables 2 and 3). Our work focused on Cryptosporidium infection in children with diarrhea, hence Cryptosporidium infection in the family members with diarrhea within 1 month remained unknown. Contacts with siblings and other family members are risk factors for children cryptosporidiosis elsewhere [34,43-45]. Our results suggested that contact with family members with diarrhea play an important role in circulating Cryptosporidium among human populations in Guangzhou region. Given that all risk factors (except for family member with diarrhea) were not significantly associated with Cryptosporidium infection, future studies are warrant to investigate the source and routes of human cryptosporidiosis in this region, such as hospital contaminations, immune status of adults with diarrhea, AIDS patients etc. For potential environmental risk factors surveyed, no patients responded contact of surface water (e.g. river, lake) or swimming pool within the past 2 months, nor sewer or wastewater effluent nearby dwelling. Therefore, the study did not determine routes of environmental exposure attributed to Cryptosporidium infection in Children. Located just the south of the Tropic of Cancer, Guangzhou has a humid subtropical climate with average monthly precipitation peaks in July and August. Interestingly, prevalence of $C$. parvum in children in the rainy season was significantly higher $(P=0.046)$ than that in other seasons (Figure 1). A previous study also found that rainy season was a risk factor for cryptosporidial infection in children $<12$ years old [46]. The higher prevalence in rainy season most likely should be caused by the environmental dissemination and transportation of oocysts facilitated by rainfalls. Future studies will be interesting to determine the sources and routes of waterborne Cryptosporidium infection in the rainy season in this region.

$C$. parvum and $C$. hominis are the two species responsible of the majority of cases of human cryptosporidiosis. In contract to $C$. hominis that predominately infects humans, $C$. parvum, a zoonotic species, infects humans and a broad range of mammals [5]. One study estimated that as many as $97 \%$ of $>2000$ human cases of cryptosporidiosis in the U.K. were due to C. parvum infection [47]. In our study, $94-97 \%$ of the 100 max sequences (standard algorithm parameters) were $C$. parvum isolates from humans or animals. Sequences of Cryptosporidium isolates from individual patients were 99.12-100\% identical to DNA sequences of $C$. parvum isolates in the GenBank. Clearly, the results indicated dominate species of Cryptosporidium in children populations in Guangzhou in the study 
period was $C$. parvum. The $C$. parvum variant 1 from suburb hospitals were $100 \%$ identical to C. parvum from humans (JX298598, JX298597) and buffalo (JX298601). C. parvum variant 2 from an urban hospital (Zencheng District hospital) was $99.87 \%$ identical to $C$. parvum from humans (KU892559, KM012046, KM012044, KM012040) and cattle (AB746195). C. parvum variant 3 from a suburb hospital was $99.87 \%$ identical to $C$. parvum from horse (KJ469985) and calf (JN120853) and $99.75 \%$ identical to $C$. parvum from humans (KU198181, KM012046). C. parvum variant 4 from an urban hospital was $100 \%$ identical to $C$. parvum from animal (unknown species) (JX948126) and $99.88 \%$ identical to $C$. parvum from humans (KU892560, KU892559) (Table 4). Results clearly showed that multiple $C$. parvum variants exist in different area of the metropolitan with different biological sources of the parasite, either from animal by zoonotic transmission or from humans by circulating among human populations. The majority of the patients' parents claimed that children had no contact with pets $(88.9 \%)$, livestock $(96.9 \%)$, or zoo animals (98.9\%). Further, the majority $(98.8 \%)$ responded that no family members work in animal farms or zoo. Due to the high homogeneity of answers, the study did not determine the animal sources of zoonotic C. parvum. Future studies in the same region should determine the prevalence and species/genotypes of Cryptosporidium in domestic animals, zoo animals and wildlife and risk factors of human exposure to zoonotic species and genotypes of Cryptosporidium.

Results of this work clearly demonstrated that Cryptosporidium is an important protozoal etiologic agent for children hospitalized with diarrhea in the Guangzhou metropolitan, China. Results suggested the need of including Cryptosporidium in routine parasitological tests for children diarrhea in hospitals in this tropical region. The existence of multiple variants of $C$. parvum indicated the source of this parasite in this region was either from humans to humans or from animals to humans caused by zoonotic transmission. Higher risks of Cryptosporidium infection exist for populations dwell proximity to suburb. To further clarify the source and routes of zoonotic transmission, future works should investigate the prevalence and species of Cryptosporidium in wildlife and domestic animals and additional routes of waterborne exposure.

\section{Acknowledgements}

The authors thanks the Guangzhou Center for Disease Control and Prevention for its' inkind support of this study. This work was supported by the University Outreach and International Programs (UOIP) Seed Grant (2012) of University of California Davis and the Project for Key Medicine Discipline Construction of Guangzhou Municipality (2013-2015-07).

\section{References}

1. Nime FA, Burek JD, Page DL, Holscher MA, Yardley JH (1976) Acute enterocolitis in a human being infected with the protozoan Cryptosporidium. Gastroenterology 70: 592-598.

2. Snelling WJ, Xiao L, Ortega-Pierres G, Lowery CJ, Moore JE, et al. (2007) Cryptosporidiosis in developing countries. J Infect Dev Ctries 1: 242-256.

3. Heymann D (2008) Cryptosporidiosis. In: Control of Communicable Diseases Manual 19th edn. American Public Health Association, Washington. pp: 157-159.

4. Slapeta J (2013) Cryptosporidiosis and Cryptosporidium species in animals and humans: a thirty colour rainbow? Int J Parasitol 43: 957-970.

5. Huang DB, Chappell C, Okhuysen PC (2004) Cryptosporidiosis in children. Semin Pediatr Infect Dis 15: 253-259.
6. Reinthaler FF (1989) Epidemiology of cryptosporidiosis in children in tropical countries. J Hyg Epidemiol Microbiol Immunol 33: 505-513.

7. Lima AA, Fang G, Schorling JB, de Albuquerque L, McAuliffe JF, et al. (1992) Persistent diarrhea in northeast Brazil: etiologies and interactions with malnutrition. Acta Paediatr Suppl 381: 39-44.

8. Tumwine JK, Kekitiinwa A, Nabukeera N, Akiyoshi DE, Rich SM, et al. (2003) Cryptosporidium parvum in children with diarrhea in Mulago Hospital, Kampala, Uganda. Am J Trop Med Hyg 68: 710-715.

9. Kotloff KL, Nataro JP, Blackwelder WC, Nasrin D, Farag TH, et al. (2013) Burden and aetiology of diarrhoeal disease in infants and young children in developing countries (the Global Enteric Multicenter Study, GEMS): a prospective, case-control study. Lancet 382: 209-222.

10. Platts-Mills JA, Babji S, Bodhidatta L, Gratz J, Haque R, et al. (2015) Pathogen-specific burdens of community diarrhoea in developing countries: a multisite birth cohort study (MAL-ED). The Lancet Glob health 3: e564-575.

11. Atwill ER, Li X, Grace D, Gannon VPJ (2012) Zoonotic waterborne pathogen loads in livestock. In: Bartram J, Bos R, Gannon V. Animal Waste, Water Quality and Human Health, World Health Organization. London, UK. IWA Publishing pp: 75-116.

12. MacKenzie WR, Schell WL, Blair KA, Addiss DG, Peterson DE, et al. (1995) Massive outbreak of waterborne Cryptosporidium infection in Milwaukee, Wisconsin: recurrence of illness and risk of secondary transmission. Clin Infect Dis 21: 57-62.

13. Hlavsa MC, Roberts VA, Anderson AR, Hill VR, Kahler AM, et al. (2011) Surveillance for waterborne disease outbreaks and other health events associated with recreational water --- United States, 2007--2008. Morbidity and Mortality Weekly Report 60: 1-32.

14. DeSilva MB, Schafer S, Kendall Scott M, Robinson B, Hills A, et al. (2016) Communitywide cryptosporidiosis outbreak associated with a surface water-supplied municipal water system--Baker City, Oregon, 2013. Epidemiol Infect 144: 274-284.

15. Ethelberg S, Lisby M, Vestergaard LS, Enemark HL, Olsen KE, et al (2009) A foodborne outbreak of Cryptosporidium hominis infection. Epidemiol Infect 137: 348-356.

16. McKerr C, Adak GK, Nichols G, Gorton R, Chalmers RM, et al. (2015) An Outbreak of Cryptosporidium parvum across England \& Scotland Associated with Consumption of Fresh Pre-Cut Salad Leaves, May 2012. PLoS One 10: e0125955.

17. Harper CM, Cowell NA, Adams BC, Langley AJ, Wohlsen TD (2002) Outbreak of Cryptosporidium linked to drinking unpasteurised milk. Commun Dis Intell Q Rep 26: 449-450.

18. Millard PS, Gensheimer KF, Addiss DG, Sosin DM, Beckett GA, et al. (1994) An outbreak of cryptosporidiosis from fresh-pressed apple cider JAMA 272: 1592-1596.

19. Robertson LJ, Chalmers RM (2013) Foodborne cryptosporidiosis: is there really more in Nordic countries? Trends Parasitol 29: 3-9.

20. Artieda J, Basterrechea M, Arriola L, Yague M, Albisua E, et al. (2012) Outbreak of cryptosporidiosis in a child day-care centre in Gipuzkoa, Spain, October to December 2011. Euro surveill 17.

21. Tangermann RH, Gordon S, Wiesner P, Kreckman L (1991) An outbreak of cryptosporidiosis in a day-care center in Georgia. Am J Epidemiol 133: 471-476.

22. Leav BA, Mackay M, Ward HD (2003) Cryptosporidium species: new insights and old challenges. Clin Infect Dis 36: 903-908.

23. Chen YG, Yao FB, Li HS, Shi WS, Dai MX, et al. (1992) Cryptosporidium infection and diarrhea in rural and urban areas of Jiangsu, People's Republic of China. J Clin Microbiol 30: 492-494.

24. Jiang Y, Ren J, Yuan Z, Liu A, Zhao H, et al. (2014) Cryptosporidium andersoni as a novel predominant Cryptosporidium species in outpatients with diarrhea in Jiangsu Province, China. BMC infect dis 14: 555 .

25. Liu H, Shen Y, Yin J, Yuan Z, Jiang Y, et al. (2014) Prevalence and genetic characterization of Cryptosporidium, Enterocytozoon, Giardia and Cyclospora in diarrheal outpatients in China. BMC infect dis 14:25. 
Citation: Chen S, Atwill ER, Zhong F, Wei Y, Hou S, et al. (2017) Prevalence and Risk Factors of Cryptosporidium Infection in Children Hospitalized for Diarrhea in Guangzhou, China. J Bacteriol Parasitol 8: 308. doi:10.4172/2155-9597.1000308

Page 8 of 8

26. Huang M, Guan L, Zhou C, Li D, Hu B (1998) Infection of cryptosporidium in child patients with diarhea in Changsha. Bulletin of Hunan Medical University 23: 255-256.

27. Wang KX, Li CP, Wang J, Pan BR (2002) Epidemiological survey of cryptosporidiosis in Anhui Province China. World J Gastroenterol 8: 371-374.

28. Zhang BX, Yu H, Zhang LL, Tao H, Li YZ, et al. (2002) Prevalence survey on Cyclospora cayetanensis and Cryptosporidium ssp. in diarrhea cases in Yunnan Province. Chinese journal of parasitology \& parasitic diseases 20: 106-108.

29. Lu J, Li CP (2004) The survey of Cryptosporidium infection among young children in kindergartens in Anhui Province. Chinese journal of parasitology \& parasitic diseases 22: 331-333.

30. Pereira MD, Atwill ER, Jones T (1999) Comparison of sensitivity of immunofluorescent microscopy to that of a combination of immunofluorescent microscopy and immunomagnetic separation for detection of Cryptosporidium parvum oocysts in adult bovine feces. Appl Environ Microbiol 65: 3236-3239.

31. Atwill ER, Harp JA, Jones T, Jardon PW, Checel S, et al. (1998) Evaluation of periparturient dairy cows and contact surfaces as a reservoir of Cryptosporidium parvum for calfhood infection. Am J Vet Res 59: 1116-1121.

32. Xiao L, Escalante L, Yang C, Sulaiman I, Escalante AA, et al. (1999) Phylogenetic analysis of Cryptosporidium parasites based on the smallsubunit rRNA gene locus. Appl Environ Microbiol 65: 1578-1583.

33. Ryan U, Xiao L, Read C, Zhou L, Lal AA, et al. (2003) Identification of novel Cryptosporidium genotypes from the Czech Republic. Appl Environ Microbiol 69: 4302-4307.

34. Pereira MD, Atwill ER, Barbosa AP, Silva SA, Garcia-Zapata MT (2002) Intra-familial and extra-familial risk factors associated with Cryptosporidium parvum infection among children hospitalized for diarrhea in Goiania, Goias, Brazil. Am J Trop Med Hyg 66: 787-793.

35. MacPherson DW, McQueen R (1993) Cryptosporidiosis: multiattribute evaluation of six diagnostic methods. J Clin Microbiol 31: 198-202.

36. Kehl KS, Cicirello H, Havens PL (1995) Comparison of four different methods for detection of Cryptosporidium species. J Clin Microbiol 33: 416-418.
37. Garcia LS, Shimizu RY (1997) Evaluation of nine immunoassay kits (enzyme immunoassay and direct fluorescence) for detection of Giardia lamblia and Cryptosporidium parvum in human fecal specimens. J Clin Microbiol 35: 1526-1529.

38. Miller K, Duran-Pinales C, Cruz-Lopez A, Morales-Lechuga L, Taren D, et al. (1994) Cryptosporidium parvum in children with diarrhea in Mexico. Am J Trop Med Hyg 51: 322-325

39. Lal A, Cornish LM, Fearnley E, Glass K, Kirk M (2015) Cryptosporidiosis: A Disease of Tropical and Remote Areas in Australia. PLoS Negl Trop Dis 9: e0004078.

40. Lal A, Fearnley E, Kirk M (2015) The Risk of Reported Cryptosporidiosis in Children Aged $<5$ Years in Australia is Highest in Very Remote Regions. Int J Environ Res Public Health 12: 11815-11828.

41. Al-Shamiri AH, Al-Zubairy AH, Al-Mamari RF (2010) The Prevalence of Cryptosporidium spp. in Children, Taiz District, Yemen. Iran J Parasitol 5: 26-32.

42. Ghenghesh KS, Ghanghish K, El-Mohammady H, Franka E (2012) Cryptosporidium in countries of the Arab world: the past decade (2002-2011). Libyan J Med 7.

43. Hunter PR, Hughes S, Woodhouse S, Syed Q, Verlander NQ, et al. (2004) Sporadic cryptosporidiosis case-control study with genotyping. Emerg Infect Dis 10: 1241-1249.

44. Sarkar R, Kattula D, Francis MR, Ajjampur SS, Prabakaran AD, et al. (2014) Risk factors for cryptosporidiosis among children in a semi urban slum in southern India: a nested case-control study. Am J Trop Med Hyg 91: 1128-1137.

45. Solorzano-Santos F, Penagos-Paniagua M, Meneses-Esquivel R, MirandaNovales MG, Leanos-Miranda B, et al. (2000) Cryptosporidium parvum infection in malnourished and non malnourished children without diarrhea in a Mexican rural population. Rev Invest Clin 52: 625-631.

46. Nchito M, Kelly P, Sianongo S, Luo NP, Feldman R, et al. (1998) Cryptosporidiosis in urban Zambian children: an analysis of risk factors. Am J Trop Med Hyg 59: 435-437.

47. Pedraza-Diaz S, Amar CF, McLauchlin J, Nichols GL, Cotton KM, et al. (2001) Cryptosporidium meleagridis from humans: molecular analysis and description of affected patients. J Infect 42: 243-250. 